\title{
Renal Function Before and After Coronary Artery Bypass G rafting (CABG): Off Pump vs. On Pump
}

\author{
SP A khter ${ }^{1}$, S K han ${ }^{2}$, T M ehdi ${ }^{3}$, M d. Nasiruddin ${ }^{4}$, FH M ollah ${ }^{5}$

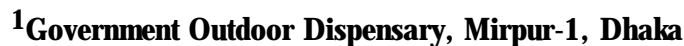 \\ 2Dept of Biochemistry, Ad-din Women's Medical College, Dhaka \\ ${ }^{3}$ Dept of Biochemistry, BSM MU, ${ }^{4} D$ ept of Biochemistry, NICVD \\ ${ }^{5}$ Dept of Biochemistry, BSM MU
}

\begin{abstract}
Coronary A rtery Bypass Grafting (CABG) is associated with a significant morbidity and mortality and several factors have been identified as predictive of complications. These include renal dysfunction and in particular renal replacement therapy. M ore than 600,000 coronary artery graft procedures are performed annually in the United States. Of those patients with coronary arterial disease $10 \%$ patients undergo CABG surgery. To explore the association of renal function between off-pump and on-pump-CABG. To evaluate the degree of impairment of renal function in on-pump, 80 patients (off-pump group $=50$, on-pump group $=30$ ) who underwent CABG were recruited from cardiac surgery dept. of $\mathrm{N}$ ational Heart Foundation and Research Institute Mirpur Dhaka and National Institute of Cardiovascular Disease (NICVD). Subjects were selected according to exclusion and inclusion criteria. Purpose and procedure of the study were explained in detail and informed written consent was taken from the study subjects. All the information of the study subject including history, clinical finding were recorded in a preformed data sheet. Serum urea and creatinine were significantly higher in on-pump group patients 12 hours after CABG. Serum urea was significantly higher and serum creatinine was slightly in onpump group in comparison to off-pump group. The mean urea and creatinine were found significantly higher in on-pump group in comparison to off-pump group and $\mathrm{ccr}$ was slightly higher lower in on-pump but not significantly decreased.
\end{abstract}

Key Words: CABG, Renal Function, off-pump CABG, On-pump CABG

\section{Introduction}

Coronary A rtery Bypass Graft (CABG) surgery among the most common operations performed in the world and account for resources expanded in the cardiovascular medicine than any other single procedure ${ }^{1}$. It is the leading cause of death of both of men and women in the United States. When blood flow is a reduced in the coronary arteries, patient may develop chest pain or angina. CABG is highly successful treatment for the relief of anagina and in selected patients for prolongation of life?2.

Coronary Artery Bypass Grafting is associated with a significant morbidity and mortality and several factors have been identified as predictive

Bangladesh J M ed Biochem 2010; 3(2): 36-41 of complications. These include renal dysfunction and in particular renal replacement therapy ${ }^{3}$. CABG is preferable in the presence of diabetes and/or heart failure when two or three coronary arteries are narrowed. If revascularization is feasible, either angioplasty or CABG is indicated when medical treatment has failed to relieve angina. During a CABG, a heart-lung machine artificially maintains circulation while the surgeon operates on the heart 4 .

After the recent development of effective devices for target vessel exposure and stabilization, beating heart techniques, e.g. offpump coronary artery bypass grafting (OPCAB) and minimally invasive direct coronary artery bypass (MIDCAB) have gained widespread 
diffusion as alternative techniques to conventional on-pump coronary artery bypass grafting ${ }^{5}$. A ccording to guideline from $\mathrm{N}$ ational Kidney Foundation (NKF) normal renal function is defined as eGFR of $90 \mathrm{ml} / \mathrm{min}$ or more. M ild, moderate or severe renal insufficiency are defined as eGFR 60-90, 30-60, and $<30$ $\mathrm{ml} / \mathrm{min}$, respectively 6 .

The spectrum of definition in published studies of acute renal failure (ARF) is striking ranging from severe (e.g. ARF requiring dialysis) to relatively modest observable increase in serum creatinine concentration (e.g., increase in serum concentration of 0.3 to $0.5 \mathrm{mg} / \mathrm{dl}$ above baseline 7 . The definition of an increase in serum creatinine of $0.5 \mathrm{mg} / \mathrm{dl}$ within $48 \mathrm{~h}$ of radiocontrast exposure in a widely cited study that showed a borderline significant difference in ARF among individual given saline infusion versus frusemide or mannitol before radiocontrast exposure. Finally, because serum creatinine is influenced by one of the potential interventions for ARF (e.g., creatinine is removed by dialysis), its specificity for renal recovery is even more problematic ${ }^{8}$.

Post-operative acute renal insufficiency continued to be a significant cause for morbidity and mortality after cardiac operations, despite advances and improvement in cardiopulmonary bypass (CPB) technology, anesthesia, intraoperative homodynamic monitoring, intensive care and antibiotic therapy9,10. Recent study has shown that, CABG, which provides good long term graft patency, can be performed on the beating heart as a viable alternative to conventional CABG i.e. on-pump. Multiple side effects on every organ system including brain, lungs, liver and kidney which are mainly because of CPBG can be avoided, by applying off-pump CABG which is important advantage ${ }^{11}$.

Kidneys are susceptible to ischemic damage because of their peculiar blood circulation. As a matter of fact, the renal medulla is perfused at a low oxygen tension; therefore, its functional reserve is limited. $M$ any per operative condition may lead to an oxygen supply/demand imbalance at the renal level: low cardiac output state, renal vasoconstriction, hemodilution, hypertension, and loss of pulsatile flow during CPB. Therefore, this pathophysiological pathway should be considered as on of the possible explanations for renal damage in the setting of cardiac surgery ${ }^{12}$.

At present, there is enough scientific information suggesting that a relative hypoperfusion (DO2 inadequate to satisfy the oxygen needs) during CPB may be responsible for different kinds of bad outcome (eg, postoperative ARF). These conditions of relative circulatory shock activate catecholamine release, associated with a reactive hyperglycemia, and play a significant role in deteriorating the postoperative outcome. Therefore, every attempts should be applied to avoid low values of DO2 during CPB, and the critical DO2 value of 260 to $270 \mathrm{~mL} \mathrm{~min}-1 \mathrm{~m}-2$ should be considered every time when setting the pump flow and maximum acceptable hemodilution degree ${ }^{13}$.

Patients can have significant reduction of their glomerular filtration rate with normal plasma creatinine level. The ability of kidneys to clear the creatinine is assessed more accurately by estimating creatinine clearance $(\mathrm{CCr})$. The formula developed by Cockcroft and Gault provides a simple and accurate way of measuring $\mathrm{CCr}$. The association between preoperative renal dysfunction and postoperative morbidity and mortality is stronger when $\mathrm{CCr}$, rather than creatinine level is used ${ }^{14}$.

Estimates of GFR are the best overall indices of the level of kidney function. Physician should estimate the level of GFR from prediction equation that take into account the serum creatinine concentration and some or the entire following variable: age, sex, and race and body size. The modification of diet in renal disease (MDRD) study and cock-croft and Gault equation provides useful estimate of (GFR) in adults.

Cockcroft and Gault equation:

(140 - age) $x$ W eight in $\mathrm{kg}$

$\mathrm{CCr}(\mathrm{ml} / \mathrm{min})=$

$72 \times$ Scr in $\mathrm{mg} / \mathrm{dl}$ 
Measurement of creatinine clearance by using timed (for example $24 \mathrm{hr}$ ) urine collection does not provide more accurate estimate of GFR than do prediction equation ${ }^{15}$.

Serum urea is less reliable marker of glomerular filtration rate than creatinine. A high protein diet, tissue breakdown, major gastrointestinal hemorrhage and corticosteroid therapy can lead to an increase in plasma urea whereas a low protein diet and liver disease can lead to a reduction. Also $40 \%-50 \%$ of filtered urea may be absorbed by the tubules, although the proportion is reduced in advanced renal failure ${ }^{16}$.

Renal impairment is a powerful independent risk factor. This may reflect the increased inflammation and oxidative stress associated with poor renal function. In addition kidney dysfunction may be associated with other physiological changes. These include high level of homocysteine, hyperuricemia, anemia, and uremia, all of which have detrimental cardiovascular effect ${ }^{17}$. Despite many limitation the cohort study on 2067 patient after 2.3 yrs follow up revealed the importance of renal function particularly eGFR in prediction short and long term prognosis of patients undergoing CABG. Future studies should determine strategies that can improve the outcome of patient with renal dysfunction 18,19 .

A voidance of cardiopulmonary bypass (CPB) by using beating heart off-pump techniques has been suggested to reduce renal damage preoperatively and result in lower rate of postoperative renal dysfunction. However, studies conducted previously in this field have provided conflicting to support this hypothsis 20,21 .

Future investigations are needed to better define the mechanisms, risk factor, magnitude and kinetics of post operative renal dysfunction and to develop clinical \& therapeutic strategies to reduce morbidity $\&$ mortality related with this devastating problem 22 .

In this study our aim was to see the degree of impairment of renal function in on-pump and to explore the association of renal function between off-pump and on-pump CABG.

\section{Methods}

This observational and prospective study was carried out from January 2008 to December 2008 in the Department of Biochemistry, Bangabandhu Sheikh M ujib Medical University (BSMMU). Ethical clearance was taken from Departmental and central ethical review committee, BSMMU. 80 patients (off-pump group $=50$, on-pump group $=30$ ) who underwent CABG were recruited from cardiac surgery dept. of National Heart Foundation and Research Institute M irpur Dhaka and National Institute of Cardiovascular Disease (NICVD). Subjects were selected according to exclusion and inclusion criteria. Purpose and procedure of the study were explained in detail and informed written consent was taken from each subject. All the information of the study subject including history, clinical finding were recorded in a preformed data sheet. W ith all aseptic precaution, $5 \mathrm{ml}$ venous blood was collected collected from each study subject for measurement of serum creatinine and serum urea. It was done preoperatively $\&$ at 12,48 hours post operatively and at discharge from the hospital. Sample was transferred immediately to clean dry test tube and was allowed to clot. Then the sample was centrifuged and serum was collected in an eppendorf tube. After labeling it was preserved at $-20^{\circ} \mathrm{C}$ until analysis. Serum creatinine was estimated by alkaline picrate method, serum urea by enzymatic (urase) method $\&$ creatinine clearance ( $\mathrm{CCr}$ ) by Cockroft and Gault equation ${ }^{23}$.

\section{Results}

Table-I shows comparison of renal parameter in different groups 12 hours after CABG. Serum urea and serum creatinine were significantly higher in Group-B and $\mathrm{CCr}$ was slightly lower in Group-B in comparison to Group-A. There was no significant difference between the two groups in respect to $\mathrm{CCr}$.

Table-ll shows comparison of renal parameter in different groups of study subjects 48 hours after $C A B G$. Sérum urea was significantly higher in Group-B in comparison to Group-A and serum creatinine was slightly higher in comparison to 
SP A khter, S K han, T M ehdi et. al

Group-A. CCr was slightly lower in Group-B in comparison to Group-A. There was no significant difference between the two groups in respect to serum creatinine and $\mathrm{CC}$.

Table-III shows comparison of renal parameters in two groups at discharge after CABG. Serum urea was significantly higher in Group- $B$ and serum creatinine was higher in Group- $B$ in comparison to group-A and $\mathrm{CCr}$ was slightly lower in Group-B in comparison to Group-A.

Table I: Comparison of renal parameters 12 hours after $C A B G$ in both the groups

\begin{tabular}{lllll}
\hline Parameter & $\begin{array}{l}\text { Group-A (Off } \\
\text { pump) } \\
(n=50) \\
\text { Mean } \pm S D\end{array}$ & $\begin{array}{l}\text { Group-B (On } \\
\text { pump) } \\
(n=30) \\
\text { M ean } \pm \text { SD }\end{array}$ & t-value & P-value \\
\hline Serum U rea & $47.88 \pm 16.197$ & $57.70 \pm 18.78$ & 2.47 & 0.02 \\
Serum Creatinine & $1.46 \pm 0.396$ & $1.48 \pm 0.361$ & 2.271 & 0.79 \\
CCr & $72.98 \pm 22.51$ & $68.26 \pm 25.34$ & 0.87 & 0.36 \\
\hline
\end{tabular}

$P$-value calculated by unpaired t-test

Table II: Comparison of renal parameters 48 hours after CABG in study subjects

\begin{tabular}{lllll}
\hline Parameter & $\begin{array}{l}\text { Group-A (Off } \\
\text { pump) } \\
(n=50) \\
\text { Mean } \pm S D\end{array}$ & $\begin{array}{l}\text { Group-B } \\
\text { (On pump) } \\
\text { (n= 30) } \\
\text { M ean } \pm S D\end{array}$ & t-value & P-value \\
\hline Serum U rea & $36.82 \pm 10.307$ & $4280 \pm 9.152$ & 2.617 & 0.011 \\
Serum Creatinine & $1.37 \pm 0.31$ & $1.53 \pm 0.27$ & 2.35 & 0.02 \\
CCr & $76.25 \pm 21.91$ & $67.28 \pm 24.88$ & 1.68 & 0.096 \\
\hline
\end{tabular}

$\mathrm{P}$-value calculated by unpaired t-test

Table III: Comparison of renal parameters at discharge after CABG in study subjects

\begin{tabular}{|c|c|c|c|c|}
\hline \multirow[t]{2}{*}{ Parameter } & \multirow{2}{*}{$\begin{array}{l}\text { Group-A (off pump) } \\
(n=50) \\
\text { Mean } \pm S D\end{array}$} & \multirow{2}{*}{$\begin{array}{l}\text { Group-B (on pump) } \\
(n=30) \\
\text { M ean } \pm S D\end{array}$} & \multirow{2}{*}{ t-value } & \multirow{2}{*}{ p-value } \\
\hline & & & & \\
\hline Serum U rea & $44.858 \pm 15.19$ & $43.43 \pm 18.50$ & 2.27 & 0.03 \\
\hline Serum Creatinine & $1.31 \pm 0.27$ & $1.42 \pm 0.32$ & 1.66 & 0.10 \\
\hline $\mathrm{CCr}$ & $79.89 \pm 18.22$ & $71.39 \pm 23.16$ & 1.82 & 0.072 \\
\hline
\end{tabular}

$P$-value calculatedby unpaired t-test

In Table-IV \& Table-V the three values were compared by One way ANOVA test was done and found highly significant difference between the three levels.

Table IV: Comparison of renal parameters preoperatively at admission, $48 \mathrm{hrs}$ after CABG \& at discharge in off pump group.

\begin{tabular}{lcccc}
\hline $\begin{array}{c}\text { Group- } \mathrm{A} \\
(\mathrm{n}=30)\end{array}$ & (Off pump) & & \\
\hline Parameter Preoperative & 48 hrs after CABG & At discharge & F-value & P-value \\
Serum Urea 28.82 & \pm 6.2847 .88 & \pm 16.19744 .85 & \pm 15.9128 .04 & $<0.001$ \\
Serum Creatinine 1.31 & \pm 0.161 .46 & \pm 0.396131 & \pm 0.2715 .46 & $<0.001$ \\
& & & & \\
CCr87.00 & \pm 18.2272 .98 & \pm 22.5179 .89 & \pm 18.226 .80 & $<0.001$ \\
\hline
\end{tabular}

P-value calculated by one way ANOVA

Table V: Comparison of renal parameters preoperatively at admission, $48 \mathrm{hrs}$ after CABG \& at discharge in on pump group

\begin{tabular}{|c|c|c|c|c|}
\hline \multirow{2}{*}{$\begin{array}{c}\text { Group-B (Of } \\
(n=30)\end{array}$} & \multicolumn{2}{|c|}{ f pump) } & \multirow[b]{2}{*}{ At discharge $\mathrm{F}$-value } & \multirow[b]{2}{*}{$P$-value } \\
\hline & \multicolumn{2}{|c|}{48 hrs after CABG } & & \\
\hline Serum Urea 31.17 & \pm 7.2657 .70 & \pm 18.7853 .43 & \pm 18.5024 .44 & $<0.001$ \\
\hline Serum Creatinine 1.18 & \pm 0.221 .48 & \pm 0.3611 .42 & \pm 0.328 .22 & $<0.001$ \\
\hline $\mathrm{CCr} 82.02$ & \pm 17.9979 .89 & \pm 18.2271 .39 & $\pm 23.16 \quad 3.12$ & $<0.05$ \\
\hline
\end{tabular}

P-value calculated by one way ANOVA

\section{Discussion}

In this observational prospective study our aim was to see the degree of renal impairment in one pump and to explore the association of renal function between off pump and on pump, CABG.

Preoperative renal parameters were similar in both the groups. All the parameters were increased significantly 12 hours and 48 hours after $C A B G$ in both the groups which is in agreement with the findings of other studies (Pramodth et al. 2003, Wen-Feng et al. 2008). Serum urea, serum creatinine were significantly higher in group $B$ in comparison to group $A$.

A nonsignificant low level of $\mathrm{CC}$ - was observed in group B. This finding is consistent with findings of other studies 24,25 .

In the prospective study by Pramodth et al. 2003, there was significant decrease in the $\mathrm{CCr}$ in one pump group from preoperative level to 24 hours post-operatively and further there was gradual increase from 24 hours to 48 hours postoperative in off pump group which is consistent with our study. It indicates that on-pump group is more prone to develop renal dysfunction after 
CABG. In a prospective randomized trial of 50 patients, a slightly greater decrease in 24 hours postoperative creatinine clearance in on-pump compared with off-pump, however there was no significant difference between pre- and postoperative renal function in either study group which is not consistent with the findings of our study.

We estimated serum creatinine, serum urea and calculated $\mathrm{CCr}$ preoperatively and 48 hours after $C A B G$ and at discharge within the groups. We found highly significant differences among the preoperative, 48 hours after CABG and at discharge which may probably due to poor renal perfusion due to hypertension. $M$ any perioperative conditions may lead to an oxygen supply/demand in balance in the renal level; such as low cardiac output state, renal vasoconstriction, hemodilution, hypotension and loss of pulsatile flow during CPB. Therefore, this path physiological condition should be considered as one of the possible explanation for renal damage in the setting of cardiac surgery. Similar findings were evident in many other studies. Here our findings are partially consistent with the previous findings 26 where renal function deteriorated significantly in first four days in on-pump CABG. These changes were not seen in the OPCAB group. It should be noted that many previous studies revealed many effects of off pump CABG such as hypotension, low cardiac output and dysrhythmia, future study involving large group will be necessary to clarify whether off-pump CABG is to be the best option to on-pump CABG.

In conclusion, the mean serum urea and creatinine were found significantly higher in onpump group in comparison to off-pump and $\mathrm{CCr}$ was slightly lower in on-pump but not significantly decreased. We also have done one way ANOVA test as the test of significance at different times (preoperatively and postoperatively) and found highly significant differences in serum urea, creatinine and $C C R$ in both the groups (off-pump, $p$ value $<0.001$, $<0.01$ and $<0.05$ for urea creatinine and CCR respectively). There were significant differences in serum creatinine, serum urea and CCR within the groups. This study demonstrates the effect of CABG (both on-pump and off-pump) on renal function. Both the groups showed significant reduction of renal function in early postoperative days (12 hrs $48 \mathrm{hrs}$ after CABG). Both serum urea and serum creatinine were raised significantly in on-pump group as compared to off-pump but CCR did not show any significant differences. From this study this can be concluded that renal function is comparative better preserved in immediate post-operative days in off-pump CABG.

\section{References}

1. Eagle KA, Guyton RA, Davidoff R, Ewy GA, Fonger J, Gardner TJ, A/AHA guidelines for Coronary Artery Bypass Graft Surgery - A report of the A merican College of Cardiology/A merican Heart Association Task Force on Practice Guidelines', Journal of the American College of Cardiology 1999; 34: 1262-1347.

2. Hillis, GS, Cuthbertson, BH, Croal, BI. Renal function, revascularization and risk. European Heart J ournal 2007; 38: 792-884

3. Hillis, GS, Croal BL, Buchan, KG, EL-Shafei, $H$, Gibson, G, Jeffry, RR, M illar, CGM, Prescott, GJ, Cuthbertson, $B H$. Renal $F$ unction and outcome from Coronary Artery Bypass Grafting: Impact on mortality after outcome 2.3 years follow up', Circulation 2006; 113:1056-1062.

4. Michaels, AD, Chatterjee, K. Angioplasty versus Bypass Surgery for Coronary Artery Disease, Circulation 2002; 102: 187-190.

5. Biglioli, P, Cannata, A, Alamanni, F, Natiato, M, Porquddu, M, Zanobini, M, Tremoli, E, Parolari, A. Biological effect of off-pump vs. on-pump coronary artery surgery: Focus on inflammation, haemostasis and oxidative stress, Eur J Cardiothoracic Surgery,2003; 24: 260-269.

6. National kidney Foundation Clinical Practice Guidelines for Chronic Kidney Disease: Evaluation, Classification and stratification, AMJ Kidney Dis 2002; 39: suppl 2SI-S246.

7. Shekar, P.S On pump and off pump coronary artery bypass grafting Circulation 2006; 113: e51-53.

8. Mehta, RL, Chertow, GM. A cute Renal failure Definition and Classification: Time for Change, A M J Soc N ephrol 2003; 14: 2178-2187. 
9. Raghuram, AR. Off-pump CABG: A Review, the internet J ournal of Cardiology 2003; I-2.

10. A scione, R, Leoyd, CT, Underwood, MJ, Gomes, WJ, Angelini, GD. On-pump versus Off-pump coronary revascularization of renal function, $A n n$ thorac Surg. 1999; 68: 493-498.

11. Peterson, E. Off-pump bypass surgery ready for the big Dance? Journal of the American Association, 2004; 291: 1897-1899.

12. Tang, A, Thomas, R, Knott, J, Nanson, J, Ohri, SK, Smith D. Beating Heart Coronary Surgery and Renal Function: A Prospective Randomized Study, Clinical Care 2005 (Sippl C).

13. Ranucci, M. Peroperative Renal Failure: Hypertension during the Cardiopulmonary Bypass', Seminars in Cardiothoracic and $V$ ascular A naesthesia, 2007; 11: 265-268.

14. A simakopoulas, G, Karagounis, AP, Valencia, 0 , Alexander, N, Howlader, M, Sarsam, MA, Chandrasekharan, V. Renal Function A fter Cardiac Surgery Off-V ersus on-pump Coronary Surgery Bypass: Analysis using the Cockroft-Gailt Formula for Estimating Creatinine Clearance, Ann Thoac Surgery 2005; 79: 2024-2031.

15. Levey, As, Coresh, J, Balk, E, Kausz, A, Steffes, MW, Hogg RJ, Perrone, RD, Lau, J, Eknoyan G. National Kidney Foundation Practice Guidelines for Chronic Kidney Disease Evaluation, Classification and Stratification, A nn Intern M ed 2007; 139(2): 137-147.

16. Traynor, J, M actier, R, Geddes CC, Fox, JG 2006, How to measure Renal Function in Clinical Practice, BM J 2006; 333: 733-737.

17. Jaegere, PPT, Suyker, W JL. Off-pump Coronary A rtery Bypass Surgery, Heart 2002; 88: 313-318.

18. Kirklin, JW Barratt-Boys, BG. Hypothermia, Circulatory Arrest and cardiopulmonary Bypass, Cardiac Surgery 2nd ED, Churchill Livingstine 1993; 127-132.
19. Holzmann, MJ, Hammar, N, A hnve, T, Pehrsson, K, Ivert, T. Renal Insufficiency and Long Term $M$ ortality and Incidence of M yocardial Infarction in Patients Undergoing Coronary A rtery Surgery Bypass Grafting, European Heart J ourna 2007; I 28: 865-871.

20. Anderson, RJ, $O$ brien, $M, M$ awhinnery, $S$, Villanueva, CB, M ortz, T, Sethi, GK, Henderson, WG, Hammermeister, KE, Grovver, FL, Shroyer, Al. Renal Failure Predisposes Patients Adverse outcome after Coronary Artery Bypass Surgery', Kidney International 1999; 55: 1057-1062.

21. MeGiffin, DC, Kirklin, JK. Cardiopulmonary Bypass For Cardiac Surgery, Surgery of the Chest by Sabiston \& Spencer 6th edition, Chapter 1995; 32: 11 W B Saunders Company, Page-1256-1268.

22. Khilji, SA, Khan, AH. A cute Renal Failure after Cardiopulmonary Bypass Surgery', J Ayab Med Coll A bottabad 2004; 16: 25-28.

23. Zamvar, VY Khan, N, U, M adhavan A, Kulatilake, N. Bitchart, EG. Clinical outcome in Coronary Artery Bypass Surgery: comparing off-pump and on-pump technique', Heart Surg. Forum 2002; 5: 109-113.

24. Pramodh, K, Vani, M uralidhar, K. Renal Function following CABG: On-pump VS Off-pump, Ind J Thorac Cradiovasc Surg 2003; 19:169-173.

25. Conlon, PJ, Smith, MS, White, WD, Newman, M F, King, S, Winn, MP, Landolf, K. A cute Renal Failure Following Cardiac Surgery', Nephrol Dial Transplant 1999; 14: 1158-1162.

26. Ooi, JSM, M, M cd, A Rahman, MR Shah, S.A, Dimon MZ. Renal outcome Following on and offpump Coronary Artery Bypass Surgery, A sian Cardio Thorac Ann 2008; 16: 468-472. 